\title{
3). SPECIAL INTERVIEW: DANIEL F. HANLEY. M.D., 1964 OLYMPIC TEAM PHYSICIAN.
}

Dr. Hanley, Olympic records seem to be broken with considerable regularity every four years. Yet we recognize that man does not change physiologically this fast. How do you explain this? Do you think medical advances can take any of the credit?

"Medical advances" is a pretty broad category. People are bigger, stronger and presumably more agile than they used to be. Evidence of this comes from profiles of Army inductees and from the records of height, weight and performance of college students over a period of years. Medicine, I am sure, has contributed to this general increase in health and stature.

There are other factors that go along with this increase in size and strength. Training techniques have been and are being refined. This is particularly true in swimming and track and field events. These are part of the great contribution of the modern coaches. There is no question that coaching techniques are much better than they used to be. Practice is now designed on a basis to aid every segment of an individual's competitive performance. Motion studies have made it possible to develop particular muscles and special skills. Special techniques are developed for the individual and this results in extra strength and ability where it is needed. There is much better attention to the utilization of practice time. There have been some rule changes which have been of benefit to individual competitors. Playing surfaces are better and more standardized. All of this adds up to a better athletic performance. If by "medical advances" you mean pills and special gimmicks, the answer is a resounding NO. There are, however, moreand more interested - physicians in the field of athletic medicine now than ever before. This, I am sure, contributes to better care.

Did you notice any outstanding differences between the medical care given our athletes and that received by the Russian Olympic team?

There were some differences. The head Russian doctors were women, and the Russians had more doctors than we did. We did exchange visits with the Russian doctors in Rome and again in Tokyo. They reviewed our program and equipment, and we reviewed theirs. They seemed to go in more for special liniments and lotions than we do, and it seems to us that the Russian physicians were more intimately concerned with the actual training techniques of the athletes. From the Russian performances in track and field and swimming, it would be safe to say that these particular spheres of influence belong to the coaches, 
and the physician should come in as we do on a consultant basis only.

The Russian physicians were most interested to know if we had any special medicines and/or techniques that we used with the track and field and swimming teams. Actually, the more I see of athletes and athletic performance, the more I am convinced that hard work, sincere desire, good competitive spirit and mental attitude are the major ingredients needed for a champion. Size and strength are of secondary importance in most sports.

Does local climate of an athlete's country affect his performance? For example, would an Indonesian athlete and one born and raised in New England be expected to achieve comparable levels of performance?

There is no question, in my opinion, that local conditions have an effect on athletic performances. There were some interesting blood studies done on athletes in Ghana that showed that many of the athletes had chronic malaria and anemia and that their performance was also low. Athletes in other countries with parasitic infestations and anemia were unable to sustain repititive high caliber performances.

You cited examples of Indonesia and New England. Just to show you that locale is not the only consideration, you know that the marathon has been considered by the Americans as sort of a New England custom, and in the Olympics little Abebe from Ethiopia walked away with it twice. The locale didn't seem to bother him very much. The heat of Rome may have been similar to the heat of Ethiopia, but the cold rain of Tokyo certainly was not.

No doubt the "location" factor will come into sharp focus with the games in Mexico in '68 where the altitude is 7500 feet.

What were the more common conditions that you had to treat among our Olympic athletes?

The full report of the activities of the medical section will be published in the official U.S. Olympic book.

Infections, particularly respiratory, gastrointestinal and skin, caused most of the problems. As one might expect, there were a considerable number of strains, sprains and muscle contusions. Many of these represented aggravations of old injuries. The day-to-day visits to the clinic in Tokyo brought essentially the same problems that are seen every day in a college health service. 
I want to add that the Olympics were a wonderful experience, one I can recommend highly to all physicians who are interested in athletics and the care of athletes. I have become a real disciple of the Olympic movement, for I am firmly convinced this is a great international venture and one that develops a lot of good will and understanding among people. Until you see it, you have no idea how heartwarming it is to see those kids at the Village helping each other, teaching each other new athletic techniques, walking around the Village arm in arm, and exchanging Olympic pins and swapping parts of their uniforms.

More countries are becoming interested in the Olympics each time. They are the greatest athletic games in the world today. I am sure they are going to be even better in the future.

Dr. Hanley is College Physician at Bowdoin College, Brunswick, Maine. He served the U.S. Olympic team at Rome in 1960 and at Tokyo in 1964. 